\title{
P051: Factors responsible for methicillin-resistant Staphylococcus aureus outbreak in the neonatal intensive care unit
}

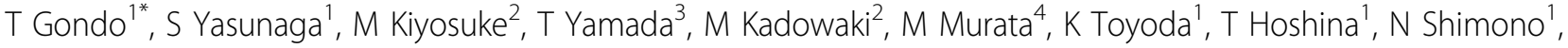 \\ $J$ Hayashi $^{1}$
}

From 2nd International Conference on Prevention and Infection Control (ICPIC 2013)

Geneva, Switzerland. 25-28 June 2013

\section{Introduction}

We observed a high incidence of methicillin-resistant Staphylococcus aureus (MRSA) outbreaks in the neonatal intensive care unit (NICU) of Kyushu University Hospital in Japan from 2010 to 2012.

\section{Objectives}

This study aimed at analyzing the cause of the outbreaks and investigating preventive measures.

\section{Methods}

This study included 556 subjects admitted to the NICU (18 beds) and the growing care unit (GCU) (13 beds) of our hospital (1,275 beds) from July 2009 to June 2012 . We retrospectively evaluated the factors responsible for MRSA outbreaks. In addition, we performed a molecular epidemiological analysis of MRSA strains by using polymerase chain reaction-based open-reading frames typing (POT) method. Based on the results, the periods were divided into Period I and II.

\section{Results}

Periods I and II were set to be July 2009-November 2010 and December 2010-June 2012, respectively. The total number of inpatients and the number of inpatients who were newly detected MRSA during Period I and II were 15,802 and 17,598, and 43 and 73 , respectively. The mean number of inpatients detected MRSA per month was 2.5 (maximum 8) during Period I and 3.8 (maximum 11) during Period II, respectively. The results of the molecular epidemiological analysis indicated that

${ }^{1}$ Center for the Study of Global Infection, Kyushu University Hospital,

Fukuoka, Japan

Full list of author information is available at the end of the article
MRSA clusters detected during Period I had disappeared before Period II, however, 4 new MRSA clusters appeared and spread throughout Period II. The duration of hospital stays per patient was considered to be a contributing factor of the outbreaks (odds ratio: 5.93, p < 0.001). Other responsible factors were bed occupancy rate in Period $\mathrm{I}(\mathrm{r}=0.57, \mathrm{p}=0.018)$ and patient care intensity in Period II $(\mathrm{r}=0.52, \mathrm{p}=0.024)$, respectively. The consumption of hand sanitizer significantly increased during Period II, when the patient care intensity increased $(\mathrm{p}<0.01)$.

\section{Conclusion}

These results suggested that MRSA outbreak might be associated with the hospital environment including bed occupancy and patient care intensity.

\section{Disclosure of interest}

None declared.

\section{Author details}

'Center for the Study of Global Infection, Kyushu University Hospital, Fukuoka, Japan. ${ }^{2}$ Department of Clinical and Laboratory Medicine, Kyushu University Hospital, Fukuoka, Japan. ${ }^{3}$ Department of Pharmacy, Kyushu University Hospital, Fukuoka, Japan. ${ }^{4}$ Department of General Internal Medicine, Kyushu University Hospital, Fukuoka, Japan.

Published: 20 June 2013

doi:10.1186/2047-2994-2-S1-P51

Cite this article as: Gondo et al:: P051: Factors responsible for methicillinresistant Staphylococcus aureus outbreak in the neonatal intensive care unit. Antimicrobial Resistance and Infection Control 2013 2(Suppl 1):P51.

\section{C)

(c) 2013 Gondo et al; licensee BioMed Central Ltd. This is an Open Access article distributed under the terms of the Creative Commons Attribution License (http://creativecommons.org/licenses/by/2.0), which permits unrestricted use, distribution, and reproduction in any medium, provided the original work is properly cited. 